3

4 5

10

6

16

\title{
Body condition as a quantitative tool to guide hand-rearing decisions in an
} endangered seabird

Joanne M. Morten ${ }^{1,2^{*}}$, Nola J. Parsons ${ }^{3}$, Christoph Schwitzer ${ }^{2}$, Marc W. Holderied ${ }^{1}$ and Richard B.

5 Sherley ${ }^{2,4,5}$

${ }^{1}$ School of Biological Sciences, University of Bristol, Bristol Life Sciences Building, 24 Tyndall Avenue, Bristol, BS8 1TQ, United Kingdom.

${ }^{2}$ Bristol Zoological Society, c/o Bristol Zoo Gardens, Clifton, Bristol, BS8 3HA, United Kingdom.

$10{ }^{3}$ Southern African Foundation for the Conservation of Coastal Birds (SANCCOB), P.O. Box 11116,

1 Bloubergrant, 7443, Cape Town, South Africa.

$12{ }^{4}$ Environment and Sustainability Institute, University of Exeter, Penryn Campus, Penryn, Cornwall, 3 TR10 9FE, United Kingdom.

$14{ }^{5}$ Animal Demography Unit, Department of Biological Sciences, University of Cape Town, Private Bag 5 X3, Rondebosch, 7701, Western Cape, South Africa.

*e-mail: jm9292@my.bristol.ac.uk 
Abstract

The use of wildlife rehabilitation for conservation is growing, but quantitative criteria are rarely used to guide whether and when to remove animals from the wild. Since 2006, large numbers of African penguin (Spheniscus demersus) chicks have been abandoned annually when adults enter moult with dependent young still in the nest. As part of conservation initiatives for this Endangered species, these chicks were collected and hand reared to fledging age. Post-release survival has been well documented; in this study we develop models to predict survival of individuals during rehabilitation with the aim of improving hand-rearing success and guiding the use of scarce resources. For 1455 chicks abandoned between 2008 and 2013, we assessed whether a chick body condition index (BCl) could predict outcome (death or release) and time spent in rearing. In addition, for a subset of 173 chicks in 2012, we assessed whether $\mathrm{BCl}$ at admission influenced chick growth rates during rehabilitation and examined whether the use of additional structural measurements and sex provided additional power to predict outcome. Models predicted an $82.9 \%$ (95\% confidence interval: $73.3-$ $89.5 \%$ ) release rate for chicks admitted with a $\mathrm{BCl}>0$, the proposed guideline for removal from colonies. This fell below $50 \%$ for $\mathrm{BCls}<-1.05 ; 66 \%$ of chicks were admitted with $\mathrm{BCls}$ between these thresholds. Adding bill length to $\mathrm{BCl}$ improved the relative model fit, but in both cases only $\sim 70 \%$ of rehabilitation outcomes were correctly predicted. Chicks that grew more quickly were more likely to be released and, for those that were released, had lower $\mathrm{BCl}$ at admission suggesting compensatory growth. Chicks were generally removed at an appropriate time to ensure successful hand-rearing. However, $32 \%$ were admitted in good condition, highlighting the importance of using adaptive management to guide wildlife rehabilitation and the allocation of conservation resources.

Keywords: Hand-rearing · Reinforcement - Seabird conservation · Wildlife management · 
Animal rehabilitation is the practice of removing wild animals that are injured, sick, orphaned or dislocated and caring for them until they can be returned to their natural habitat (Molony et al. 2006; Wimberger, Downs and Boyes, 2010; Guy, Curnoe and Banks, 2013). Worldwide, the use of rehabilitation as a conservation tool is growing, requiring resources such as time and funding (Molony et al. 2006; Guy et al. 2013). Although some species suffer high mortality in temporary captivity (e.g. Kirkwood and Best, 1998; Kirkwood 2003) or postrelease (e.g. Fajardo, Babiloni and Miranda, 2000), others can be successfully rehabilitated and restored to natural populations (Lunney et al. 2004, Wolfaardt et al. 2008). Identifying variables that can predict rehabilitation success would allow conservation resources to be focused on animals more likely to survive to release and beyond (Molony et al. 2007). However, quantitative tools of this nature are rarely developed and results can be conflicting (Molina-López, Casal and Darwich, 2015). For example, body mass at admission is often al. 2013).

60

African penguins (S. demersus) have been rehabilitated at the Southern African Foundation for the Conservation of Coastal Birds (SANCCOB; Cape Town) since 1968, with high release and restoration rates (Randall, Randall and Bevan, 1980; Barham et al. 2006; Wolfaardt et al. 2008). Rehabilitation is considered an important conservation tool for this Endangered species (Crawford, Kemper and Underhill, 2013). Penguins usually enter rehabilitation as a result of oiling, injury, or as abandoned chicks (Parsons and Underhill 2005). Chicks were initially hand reared in large numbers after adults were fouled in oil spills in 1994 and 2000 (e.g. Barham et al. 2006; Barham et al. 2008). More recently, many chicks 
have been admitted for hand-rearing due to adult penguins entering moult with dependent chicks still in the nest, likely because of prey scarcity (Sherley et al. 2014). African penguins moult their whole plumage simultaneously, so lose their waterproofing and are unable to catch food for c. 21 days (Cooper, 1978). Any unfledged chicks are abandoned to starve (Sherley et al. 2014). Between 2001 and 2013, as few as 82 (2001) and as many as 841 (2006) such chicks have been collected annually for hand-rearing and release back into the wild (Parsons and Underhill 2005; Sherley et al. 2014).

Rehabilitating abandoned chicks aims to bolster this declining population while methods are developed to establish breeding colonies where prey availability is higher (Schwitzer et al. 2013). Hand-reared chicks have similar survival and recruitment rates to wild progeny (Barham et al. 2008, Sherley et al. 2014). Thus, maximising release rates could provide conservation benefit in line with the national and international recommendations to reinforce populations and establish techniques for conservation translocations (Ellis, Croxall and Cooper, 1998; Crawford et al. 2013). Until the recent development of a body condition index, colony managers lacked quantitative criteria to assess whether individual chicks had been abandoned (Lubbe et al. 2014; Sherley et al. 2014). Instead, abandonment was determined qualitatively (by visual assessment) or chicks were removed en-masse to minimise disturbance once a high proportion of the adult population had initiated moult (Sherley et al. 2014).

A body condition index $(\mathrm{BCl})$ attempts to determine the proportion of mass available to an individual as metabolic energy reserves, while correcting for structural size (e.g. Jakob, Marshall and Uetz, 1996). $\mathrm{BCl}$ at admission may, therefore, be more informative to rehabilitators than the commonly used body mass (e.g. Molony et al. 2007; Vanstreels et al. 2013). Lubbe et al. (2014) developed a $\mathrm{BCl}$ for African penguin chicks using mass and structural measurements. This provided a quantitative tool to assess likelihood of chick 
abandonment by establishing a lower limit $\left(5^{\text {th }}\right.$ percentile) for chicks known to have fledged naturally $(\mathrm{BCl}=0)$. Chicks with $\mathrm{BCls}<0$ are at heightened risk of starvation, so should be removed for hand-rearing (Lubbe et al. 2014, Sherley et al. 2014). However, whether a very low $\mathrm{BCl}$ at admission also influences survival during rehabilitation has not been tested. In addition, nutrient deficiencies during early development may constrain future growth (Dmitriew 2011) and increase levels of stress hormones (Honarmand, Goymann and Naguib, 2010). Good growth rates are usually associated with improved survival in the wild (e.g. Coulson and Porter 1985) and during rehabilitation (e.g. Molony et al. 2007). Moreover, minimising time in captivity could reduce disease susceptibility and increase immune suppression linked to increased glucocorticoid levels resulting from proximity to humans (Siegel 1980; Ellenburg et al. 2006, 2007). However, investing in compensatory growth once resource availability improves (i.e. entering captivity) can increase oxidative stress and decrease survival (Geiger et al. 2012; Stier et al. 2014), so may also reduce the likelihood of chick release.

Using data from chicks abandoned between 2008 and 2013, we therefore aimed to determine whether:

1. $\mathrm{BCl}$ at admission could predict rehabilitation outcome and time in rehabilitation, with the aim of guiding improvements in rehabilitation efficiency;

2. the use of additional morphometric measurements and sex could improve our ability to predict rehabilitation outcome;

3. the outcome of, and time in rehabilitation, depended on the growth rate chick attain and, in turn, whether these growth rates were related to $\mathrm{BCl}$ at admission.

\section{Materials and methods}

Between September 2008 and December 2013, the head length $(\mathrm{mm})$ and mass $(\mathrm{g})$ were measured for all African penguin chicks admitted to SANCCOB, Cape Town. Chicks were 
123 classified into life stages at admission: P2 - medium, down feathers; P3 - large, down

124 feathers; P4 - less than 50\% down feathers; and Blue - full juvenile plumage (Sherley et al. 2014). Surviving chicks were released in juvenile plumage, once they had satisfied SANCCOB's conditions for release (Supporting Information; Parsons and Underhill 2005). Time between admission and death or release (hereafter 'time in rehabilitation') was recorded for each chick to the nearest full day. Chicks were excluded from our analyses if records indicated admission for reasons other than abandonment (e.g. injury).

For a subset of chicks admitted between September 2012 and February 2013 (2012/13 cohort), we measured mass every c. 7 days until release or death (in $\mathrm{g}$, using an electronic balance) and measured bill length, bill depth (both in $\mathrm{mm}$ with Vernier callipers), foot length and flipper length (both in $\mathrm{mm}$ with a ruler) once within 7 days of admission (see Supporting Information for details). For this subset, we also used necropsy results (for those that died) or genetic testing to determine sex. 
To determine whether $\mathrm{BCI}$ was a predictor of rehabilitation outcome, we used a generalisedlinear mixed-model $(G L M M)$ with a binary response (died $=0$, released $=1)$, a logit link function and $\mathrm{BCl}$ at admission as the only fixed effect. Because release probability might vary between years (as a result of e.g. changes in protocols) and depend on a chick's lifestage at admission (older chicks more likely to be released), we used life-stage (P2-Blue) nested in the year of admission to specify random intercepts. We specified this model using all but a random subsample of 100 chicks admitted between 2008 and 2013 (the test dataset). We used this model to predict the release rate $( \pm 95 \%$ confidence intervals, $\mathrm{Cl})$ for chicks admitted at $\mathrm{BCl}=0$ (the proposed threshold for chick removal), $\mathrm{BCl}=0.51$ (mean $\mathrm{BCl}$ at Robben Island in 2004; Lubbe et al. 2014), and the $\mathrm{BCl}$ at admission resulting in a predicted release rate $<50 \%$. We assessed the predictive power of the model using marginal $R^{2}$ (Nakagawa and Schielzeth 2013; MuMIn library v. 1.15.1) and binary crossvalidation (died or released) using the test dataset.

To test whether there was a relationship between time in rehabilitation and $\mathrm{BCl}$ at admission, we separated the chicks into two outcome groups (released and died). Since time in rehabilitation was measured to the nearest day, and thereby approximated count data, we used a negative binomial GLMM (nbGLMM) to account for overdispersion with a log-link function and random intercepts as above.

Additional morphometric measurements and sex as predictors of rehabilitation outcome We used the seven parameters (mass, head length, bill length, bill depth, foot length, flipper length and $\mathrm{BCl}$ ) along with sex, to build a candidate set of multiple regression models to predict rehabilitation outcome. We first checked the correlation between the explanatory variables (Supporting Information Table S1) and any pair where $r_{s} \geq|0.7|$ were not combined to avoid distortion of parameter estimates (Dormann et al. 2013). We used 
maximum of three fixed effects in each model (Supporting Information Table S2). Akaike's Information Criterion for small sample sizes (AICc) was used to select the model containing one explanatory variable with the lowest AICc value. This model was used as the base model and each of the remaining (non-correlated) variables were added to it in turn up to a maximum of three explanatory variables (Table S2). Models were ranked by AICc weight, with model averaging used for inference where several models were within a $\triangle \mathrm{AICc}<2$ of the best fitting model (Burnham and Anderson 2002).

\section{Growth rates and their relationship with rehabilitation outcome}

We used the repeated mass measurements to estimate growth rates for the 2012/13 cohort.

Following Sherley (2010), we excluded penguin chicks that were measured over $<10$ days in total and generated Gompertz growth coefficients following the Tjørve and Underhill (2009) method designed for use when age is unknown (e.g. Bonato et al. 2013). The Gompertz growth coefficient $\left(k_{G}\right)$ for each bird was estimated as:

$$
k_{G}=\frac{\log \left(-\log \left(\frac{M_{1}}{M_{A}}\right)\right)-\log \left(-\log \left(\frac{M_{2}}{M_{A}}\right)\right)}{t_{2}-t_{1}}
$$

where $M_{1}=$ mass $(\mathrm{g})$ at time $t_{1}, M_{2}=$ mass $(\mathrm{g})$ at time $t_{2}, M_{A}=\operatorname{asymptotic}$ mass $(3500 \mathrm{~g}$, Sherley 2010) and log = natural logarithm. To determine if growth rates influenced rehabilitation outcome, we used a GLMM with a binary response (died $=0$, released $=1$; binomial error, logit link), with random intercepts specified using the life-stage of each chick. Finally, we used two linear-mixed models (LMM) to explore the relationship between body condition at arrival and growth rate separately for each of the rehabilitation outcomes (died or released). Residuals checks confirmed conformity to linear model assumptions. 
Unless otherwise specified, all statistics were performed in R v. 3.2.1, mixed-models were specified using the Ime4 library (v. 1.1-9), means \pm 1 SD are presented where data were normally distributed and medians and the interquartile range (IQR) where they were not.

\section{Results}

$\mathrm{BCl}$, time in rehabilitation and rehabilitation outcome

We calculated BCls for 1455 chicks, of which $71.8 \%$ were released. For those released $(n=$ 1045) mean $\mathrm{BCl}=-0.15 \pm 0.43$ (range: $-1.23-1.38)$, while for those that died $(n=410)$ mean $\mathrm{BCl}=-0.41 \pm 0.41$ (range: $-1.31-0.98$ ). Despite substantial overlap between the groups, all chicks with $\mathrm{BCl}>0.98$ were released (Fig. 1) and rehabilitation outcome was related to $\mathrm{BCl}$ at admission (GLMM: $\chi^{2}=75.7, \mathrm{p}<0.001$, coefficient estimate $=1.51$, Fig. 1 ). The model predicted release rate was $82.9 \%(95 \% \mathrm{Cl}: 73.3-89.5 \%)$ at $\mathrm{BCl}=0$ and $91.3 \%$ for $\mathrm{BCl}=0.51$ (Fig. 1). This fell to $50 \%$ (i.e. equal chance of dying and surviving) once $\mathrm{BCl}$ was $\leq-1.05$ (Fig. 1). Only 33 chicks were admitted with BCls below this, of which $64 \%$ died. In total, $66 \%$ of chicks were admitted with $\mathrm{BCl}$ values between -1.05 and 0 . For $\mathrm{BCl}$ alone, the marginal $R^{2}=0.104$ and the model only correctly classified $69 \%$ of the test set (Table 1 ).

Chicks were at SANCCOB for a median of 52 (IQR: 39-63) days before release, or 8 (4-36) days before they died. Time in rehabilitation was positively related to $\mathrm{BCl}$ for chicks that died (nbGLMM: $\chi^{2}=28.0, \mathrm{p}<0.001$, coefficient estimate $=0.96$, Fig. $2 \mathrm{~A}$ ), and negatively related to $\mathrm{BCl}$ for those released ( $\mathrm{nbGLMM}: \chi^{2}=12.3, \mathrm{p}<0.001$ ), although this latter effect size was small (coefficient estimate $=-0.11$, Fig. 2B).

\section{Additional morphometric measurements and sex}

The additional morphometric measurements were made on 173 chicks in the 2012/13 cohort (79 = male, $94=$ female). Head length, bill length, flipper length and bill depth were strongly correlated (Table S1), so not combined in the same model. Four candidate models had a 
$\triangle \mathrm{AICc}<2$ and contributed to $>90 \%$ of the summed AICc weight (Table 2). Two variables occurred in all four models (Table 2) and had positive effects on rehabilitation outcome (model averaged results): $\mathrm{BCl}$ (coefficient estimate: $2.73, \mathrm{z}=3.11, \mathrm{p}=0.002$ ) and bill length (coefficient estimate: $z=0.17, p=0.008$; Supporting Information Fig. S1). The model containing only these two variables explained $24.3 \%$ of the variation in rehabilitation outcome (marginal $\mathrm{R}^{2}$, Table 2), but predicted responses based on the model averaged results only correctly classified the outcome of $71 \%$ of the 173 chicks. None of the three other parameters in these four models (Mass, Sex and foot length) significantly influenced rehabilitation outcome (all model averaged p-values $>0.05$ ).

\section{Growth rates and rehabilitation outcome}

Mass was measured at a median interval of 7 days $(I Q R=7)$ for 220 chicks, of which 39 $(18 \%)$ died and $181(82 \%)$ were released. The mean growth rate of chicks that died was $0.011 \pm 0.015$, compared to $0.028 \pm 0.009$ for those released. Chicks with lower growth rates were significantly less likely to survive rehabilitation (GLMM: $\chi^{2}=35.1, p<0.001$; Fig. 3A). For chicks that died, there was no relationship between $\mathrm{BCl}$ and growth rate $\left(\mathrm{LMM}: \chi^{2}=2.1\right.$, $p=0.15$, coefficient estimate $=-0.012$, Supporting Information Fig. S2), while for those released, chicks with lower $\mathrm{BCl}$ grew faster during rehabilitation $\left(\mathrm{LMM}: \chi^{2}=15.4, \mathrm{p}<0.001\right.$, coefficient estimate $=-0.006$, Fig. 3B).

\section{Discussion}

Rearing of chicks unlikely to survive naturally has the potential to contribute significantly to conservation efforts for threatened bird species (e.g. Jones 2004). In African penguins, chicks partially hand reared survive and recruit as well as naturally-reared chicks (Barham et al. 2008; Sherley et al. 2014). However, there is a great variation in the number of chicks that enter rehabilitation annually. For instance, there were almost ten times as many chicks in 2010 (432) as in 2008 (45). In years with large influxes of chicks, or in the event of future 
254

large oil spills, when resources may be stretched, quantitative tools to guide decision making would help direct efforts towards those animals most likely to survive. Our results suggest $\mathrm{BCl}$ is useful for this purpose.

\section{$\mathrm{BCl}$, time in rehabilitation and rehabilitation outcome}

The Lubbe et al. (2014) $\mathrm{BCl}$ is now used in colonies to determine whether and when chicks need to be removed and hand reared. Our results identified $\mathrm{BCl}=-1.05$ as a lower limit; below this the chances of successful rehabilitation were $<50 \%$. The results also supported the proposed threshold of chick removal once $\mathrm{BCl}$ falls below 0 and we recommend colony managers prioritise the removal of chicks with $\mathrm{BCls}>-1.05$ and $<0$. Although the release rate continued to increase with a $\mathrm{BCl}$ at admission $>0$, it cannot be certain that these chicks had been abandoned since $\mathrm{BCl}=0$ represents the $5^{\text {th }}$ percentile from a cohort of chicks which all fledged naturally (Lubbe et al. 2014). Despite the success of hand rearing (e.g. Barham et al. 2008), unnecessary removal of wild birds should be avoided and $32 \%$ of chicks in this study were admitted with $\mathrm{BCl}>0$, thus may have survived in the wild. In some cases, disturbance caused by assessing chicks individually will still need to be balanced against the cost of removing chicks in good condition (see Sherley et al. 2014), but our results demonstrate the importance of incorporating data-driven indices into decisions on when to remove animals for rehabilitation or rearing. As a predictive model, however, $\mathrm{BCl}$ overestimated the number of chicks that would be released. Though it would be useful to rapidly identify chicks in need of critical attention at admission (Supporting Information Fig. S3), it may not be prudent to use this model to label chicks as unable to survive rehabilitation accept in the wake of large disasters, such as oil spills, when resources are overextended (Crawford et al. 2000).

Chicks with greater $\mathrm{BCls}$ at admission also spent less time in rehabilitation before release, although the effect was small. Chicks admitted at younger life-stages, but with a 'good' $\mathrm{BCl}$, 
still needed to stay until they have reached fledging size and developed waterproof plumage. Fledgling periods are usually $\sim 70-80$ days in the wild (Sherley et al. 2013) and chick admitted to SANCCOB between 2001 and 2002 were released after 65 days on average (Parsons and Underhill 2005). Therefore, regardless of admission $\mathrm{BCl}$, chicks remain in rehabilitation until they reach the 'Blue' life-stage for release, which is why the effect was small. Clearly, factors other than $\mathrm{BCl}$ need to be considered to develop models to accurately predict mortality and minimise time spent in rehabilitation.

\section{Additional morphometric measurements and sex}

The additional covariates, particularly bill length, marginally improved our capacity to predict outcome over $\mathrm{BCl}$ alone. $\mathrm{BCl}$ is simple to calculate, currently used by field researchers and managers, and already measured as standard upon admission to SANCCOB. So, while it may be possible to improve outcome prediction with additional morphometric measurements it may not be worth the additional time-costs, at least for those parameters tested here.

Of course, many other variables not measured in this study could affect rehabilitation outcome; for example, illness during rehabilitation, food consumption and glucocorticoid levels. Since our aim was to test models that might predict outcome, only variables measured in the first seven days after admission were evaluated. While outcome could also be affected by factors occurring after this period, they would not be useful rehabilitation outcome predictors, but could explain a larger proportion of the variation than $\mathrm{BCl}$ and bill length.

Sex in particular, should be a focus for future research. Spheniscid sexual dimorphism is small, but males tend to be larger (Cooper, 1972). In diving seabirds, larger individuals can dive deeper and for longer, so exploit prey in more of the water column (e.g. Cook et al. 2013). Thus female African penguins may be suffering higher mortality as a result of their 
smaller size as prey has become scarce (Pichegru et al. 2013; Pichegru and Parsons, 2014). Higher female mortality has been observed in adult and juvenile penguins being admitted to SANCCOB (Pichegru and Parsons, 2014) and we observed a trend towards higher rehabilitation success in male than female chicks (Table 2). Skewed adult sex ratios are common in threatened populations, such as the African penguin, and may increase the risk of decline (Pichegru and Parsons, 2014). The sex of chicks cannot be determined reliably using morphometrics and molecular DNA testing is costly (Pichegru and Parsons, 2014). The risk of skewing the adult population warrants further investigation into the sex ratio of chicks released (Goldsworthy et al. 2000). Previously sex ratio has only been investigated in chicks that died (Pichegru and Parsons, 2014), while the cohort sexed here was small and only from one year. Thus, we suggest that the sex ratio be determined on a larger sample of chicks, for both rehabilitation outcomes, over several years.

\section{Growth rates and rehabilitation outcome}

Chicks with lower growth rates were significantly less likely to survive rehabilitation, reflecting patterns seen in fledgling probabilities in wild penguin chicks (Wolfaardt et al. 2008) and other seabirds (e.g. herring gulls Larus argentatus, Kadlec, Drury and Onion, 1969). However, a slow growth rate is usually not the ultimate cause of mortality in wild populations, rather slower growing chicks are at risk from environmental hazards (such as predation or hypothermia) for longer than those growing rapidly (Kadlec et al. 1969). Although hand-reared chicks would not encounter such hazards, a slow growth rate and prolonged period to reach the mass necessary for release, could result in chronic stress, leading to higher disease susceptibility or other complications (e.g. pododermititis; Sherley et al. 2014).

Finally, release chicks admitted with a lower $\mathrm{BCl}$ grew faster during rehabilitation, suggesting compensatory growth as previously demonstrated in African penguin chicks (Heath and 
Randall, 1985). Growth acceleration once an animal has moved from a poor quality environment (in this case abandonment) to a high quality environment (rehabilitation) is commonly through hyperphagia (Wilson and Osbourn, 1960; Metcalfe and Monaghan, 2001). Since all chicks in this study had the same diets during rehabilitation, feeding more to chicks exhibiting behaviour associated with hunger (e.g. more persistent begging) seems the likely cause of compensatory growth. Fledging body condition may impact subsequent survival in penguins (Saraux et al. 2011), so it is important that chicks leave with good BCI to ensure successful recruitment into the breeding population. However, compensatory growth may carry future physiological costs (e.g. elevated resting metabolic rate, oxidative stress levels and telomere erosion) negatively affecting long-term survival (Criscuolo et al. 2008; Geiger et al. 2012; Stier et al. 2014). Thus, further investigation into whether growth rates in rehabilitation impact individual post-release survival is warranted.

\section{Conclusions}

Maximising rehabilitation success of abandoned chicks has important implications for African penguin conservation, particularly in light of plans to use conservation translocations to establish new colonies in favourable breeding localities for this Endangered species (Sherley et al. 2014). Using cohorts of abandoned chicks across six breeding seasons, we have shown that chicks admitted with better $\mathrm{BCl}$, the variable used in colonies to determine chick abandonment, were more likely to survive rehabilitation. Only $2.3 \%$ of chicks admitted during the study period had a $\mathrm{BCl}$ so low that there was $\mathrm{a}<50 \%$ chance of release. This indicates that intervention occurs when successful rehabilitation is likely for the vast majority of cases. However, $32 \%$ were admitted in good condition and would likely have fledged in the wild, highlighting the importance of using adaptive management to guide the need for wildlife rehabilitation and its timing. Incorporating these critical $\mathrm{BCl}$ thresholds into future management will ensure that abandoned chicks, and those still being fed, both have the maximum chance of survival to fledging. 


\section{Acknowledgments}

364

This study contributes to the African Penguin Chick Bolstering Project (CBP) and benefitted from donations to the CBP from 46 supporter organisations (listed at http://tinyurl.com/SANCCOB-CBP). In addition, the Earthwatch Institute (NJP, RBS), the Leiden Conservation Foundation (RBS) and our institutions provided financial support. We thank the staff and volunteers of SANCCOB, CapeNature, the City of Cape Town's Environmental Resource Management Department, the IFAW oil spill response team who helped to rear the chicks.

\section{References}

Barham, P.J., Crawford, R.J.M., Underhill, L.G., Wolfaardt, A.C., Barham, B.J., Dyer, B.M., Leshoro, T.M., Meÿer, M.A., Navarro, R.A., Oschadleus, D., Upfold, L., Whittington, P.A. \& Williams, A.J. (2006). Return to Robben Island of African penguins that were rehabilitated, relocated or reared in captivity following the Treasure oil spill of 2000. Ostrich 77, 202-209

Barham, P.J., Underhill, L.G., Crawford, R.J.M., Altwegg, R., Leshoro, T.M., Bolton, D.A., Dyer, B.M. \& Upfold, L. (2008). The efficacy of hand-rearing penguin chicks: evidence from African Penguins (Spheniscus demersus) orphaned in the Treasure oil spill in 2000. Bird. Conserv. Int. 18, 144-152

Bonato, M., Evans, M.R., Hasselquist, D., Sherley, R.B., Cloete, S.W.P. \& Cherry, I.C. (2013). Ostrich chick humoral immune responses and growth rate are predicted by parental immune responses and paternal colouration. Behav. Ecol. Sociobiol. 67, $1891-1901$

Burnham, K.P. \& Anderson, D.R. (2002). Model selection and multimodel inference: a practical information-theoretic approach. $2^{\text {nd }}$ ed, New York: Springer -Verlag

Cook, T.R., Lescroël, A., Cherel, Y., Kato, A. \& Bost, C-A. (2013). Can foraging ecology drive the evolution of body size in a diving endotherm? PLOS ONE 8, e56297 
Cooper, J. (1972). Sexing the jackass penguin. Safring News 1, 23-25

Cooper, J. (1978). Moult of the Black-footed penguin. Int. Zoo. Yearb. 18, 22-27

Coulson, J.C. \& Porter, J.M. (1985). Reproductive success of the Kittiwake Rissa tridactyla: the roles of clutch size, chick growth rates and parental quality. Ibis 127, 450-466

Crawford, R.J.M., Davis, S.A., Harding, R.T., Jackson, L.F., Leshoro, T.M., Mëyer, M.A., Randall, R.M., Underhill, L.G., Upfold, L., Van Dalsen, A.P., van der Merwe, E., Whittington, P.A., Williams, A.J., \& Wolfaardt, A.C. (2000). Initial impact of the Treasure oil spill on seabirds off western South Africa. S. Afr. J. Mar. Sci. 22, 157176

Crawford, R.J.M., Kemper, J. \& Underhill, L.G. (2013). African Penguin Spheniscus demersus. In Penguins Natural History and Conservation: 211-231. Garcia Borboroglu, P. \& Boersma, P.D. (Eds.). University of Washington Press, Seattle.

Criscuolo, F., Monaghan, P., Nasir, L. \& Metcalfe, N.B. (2008) Early nutrition and phenotypic development: 'catch-up' growth leads to elevated metabolic rate in adulthood. Proc. R.Soc.B. $\mathbf{2 7 5}, 1565-1570$

Dmitriew, C.M. (2011) The evolution of growth trajectories: what limits growth rate? Biol. Rev. 86, 97-116

Dormann, C.F., Elith J., Bacher, S., Buchmann, C., Carl, G., Carré, G., Marquéz, J.R.G., Gruber, B., Lafourcade, B., Leitão, P.J., Münkemüller, T., McClean, C., Osborne, P.E., Reineking, B., Schröder, B., Skidmore, A.K., Zurell, D. \& Lautenbach, S. (2013). Collinearity: a review of methods to deal with it and a simulation study evaluating their performance. Ecography 36, 27-46

Ellenburg, U., Mattern, T., Seddon, P.J. \& Jorquera, G.L. (2006). Physiological and reproductive consequences of human disturbance in Humboldt penguins: the need for species- specific visitor management. Biol. Conser. 133, 95-106 
Ellenburg, U., Setiawan, A.N., Cree, A., Houston, D.M. \& Seddon, P.J. (2007). Elevated hormonal stress response and reduced reproductive output in Yellow-eyed penguins exposed to unregulated tourism. Gen. Comp. Endocrinol. 152, 54-63

Ellis, S., Croxall, J.P. \& Cooper, J. (1998). Penguin conservation assessment and management plan. Apple Valley, USA: IUCN/ SSC Conservation Breeding Specialist Group

Fajardo, I., Babiloni, G. \& Miranda, Y (2000). Rehabilitated and wild barn owls (Tyto alba): dispersal, life expectancy and mortality in Spain. Biol. Conser. 94, 287-295

Geiger, S., Le Vaillant, M., Lebard, T., Reichert, S., Stier, A., Le Maho, Y. \& Criscuolo F. (2012). Catching-up but telomere loss: half-opening the black box of growth and ageing trade-off in wild king penguin chicks. Mol. Ecol. 21, 1500-1510

Goldsworthy, S. D., Giese, M., Gales, R. P., Brothers, N. \& Hamill, J. (2000). Effects of the Iron Baron oil spill on little penguins (Eudyptula minor). II. Post-release survival of rehabilitated oiled birds. Wildl. Res. 27, 573-582

Guy, A.J., Curnoe, D. \& Banks, P.B. (2013). A survey of current mammal rehabilitation and release practices. Biodivers. Conserv. 22, 825-837

Heath, R.J.M. \& Randall, R.M. (1985) Growth of Jackass penguin chicks (Spheniscus demersus) hand reared on different diets. J. Zool. 205, 91-105

Honarmand, M., Goymann, W. \& Naguib, M. (2010). Stressful dieting: Nutritional conditions but not compensatory growth elevate corticosterone levels in zebra finch nestlings and fledglings. PLOS ONE 5, e12930

Jakob, E.M., Marshall, S.D. \& Uetz, G.W. (1996). Estimating fitness: a comparison of body condition indices. Oikos 77, 61-67

Jones, C.G. (2004). Conservation management of endangered birds. In Bird Ecology and Conservation: a handbook of techniques: 269-301. Sutherland, W.J., Newton, I. \& Green, R.E. (Eds.). University of Oxford Press, Oxford. 
Kadlec, J.A., Drury, W.H.Jr. \& Onion, D. K. (1969). Growth and mortality of Herring gull chicks. Bird-Banding. 40, 222-233

Kelly, A., Halsted, C., Hunter, D., Leighton, K., Grogan, A. \& Harris, M. (2011). Factors affecting the likelihood of release of injured and orphaned woodpigeons (Columba palumbus). Anim. Welf. 20, 523-534

Kirkwood, J.K. \& Best, R. (1998). Treatment and rehabilitation of wildlife causalities: legal and ethical aspects. In Practice 20, 214-216

Kirkwood, J.K. (2003) Introduction: wildlife casualties and the veterinary surgeon. In BSAVA Manual of Wildlife Casualities: 1-6. Mullineaux, E., Best, D. \& Cooper, J.E (Eds.). British Small Animal Veterinary Association, Gloucester, UK

Lubbe, A., Underhill, L.G., Waller, L.J. \& Veen J. (2014). A condition index for African penguin Spheniscus demersus chicks. Afr. J. Mar. Sci. 36, 143-154

Lunney, D., Gresser, S.M., Mahon, P.S. \& Matthews, A. (2004). Post-fire survival and reproduction of rehabilitated and unburnt koalas. Biol. Conser. 120, 567-575

Metcalfe, N.B. \& Monaghan, P. (2001). Compensation for a bad start: grow now, pay later? Trends. Ecol. Evol. 16, 254-260

Molina-López, R.A., Casal, J. \& Darwich, L. (2015). Prognostic indicators associated with early mortaility of wild raptors admitted to a wildlife rehabilitation centre in Spain. Vet. Quart. 35, 9-15

Molony, S.E., Dowding, C.V., Baker, P.J., Cuthill, I.C. \& Harris, S. (2006). The effect of translocation and temporary captivity on wildlife rehabilitation success: An experimental study using European hedgehogs (Erinaceus europaeus). Biol. Conser. $130,530-537$

Molony, S.E., Baker, P.J., Garland, L., Cuthill, I. C. \& Harris, S. (2007). Factors that can be used to predict release rates for wildlife centres. Anim. Welf. 16, 361-367

Nakagawa, S. \& Schielzeth, H. (2013). A general and simple method for obtaining $\mathrm{R}^{2}$ from generalized linear mixed-effects models. Methods. Ecol. Evol. 4, 133-142 
Parsons, N.J. \& Underhill, L.G. (2005). Oiled and injured African penguins Spheniscus demersus and other seabirds admitted for rehabilitation in the Western Cape, South Africa, 2001 and 2002. Afr. J. Mar. Sci. 27, 289-296

Pichegru, L. \& Parsons, N. J. (2014) Female-biased mortality in African penguins. Afr. J. Mar. Sci. 36, 279-282

Pichegru, L., Cook, T.R., Handley, J., Voogt, N., Watermeyer, J., Nupen, L., McQuaid, C.D. (2013) Sex-specific foraging behavior and a field sexing technique for endangered African penguins. Endanger. Species Res. 19, 255-264

Randall, R.M., Randall, B.M. \& Bevan, J. (1980). Oil pollution and penguins- is cleaning justified? Mar. Pollut. Bull. 11, 234-237

Rodrigues, S.C., Adornes, A.C., Santos-Filho, E.A., Pinho da Silva-Filho, R. \& Colares, E.P. (2010). Surviving probability indicators of landing juvenile Magellanic Penguins arriving along the southern Brazilian coast. Braz. Arch. Biol. Tech. 53, 419-424

Saraux, C., Viblanc, V.A., Hanuise, N., Le Maho, Y. \& Le Bohec C. (2011). Effects of individual pre-fledging traits and environmental conditions on return patterns in juvenile king penguins. PLOS ONE 6, e20407

Schwitzer, C., Simpson, N., Roestorf, M. \& Sherley, R.B. (2013). The African Penguin Chick Bolstering Project: A One Plan approach to integrated species conservation. WAZA Magazine 14, 23-26

Sherley, R.B. (2010). Factors influencing the demography of endangered seabirds at Robben Island, South Africa: implications and approaches for management and conservation. PhD thesis, University of Bristol.

Sherley, R.B., Underhill, L.G., Barham, B.J., Barham, R.J., Coetzee, J.C., Crawford, R.J.M., Dyer, B.M., Leshoro, T.M. \& Upfold, L. (2013). Influence of local and regional prey availability on breeding performance of African penguins Spheniscus demersus. Mar. Ecol. Prog. Ser. 473, 291-301 
Sherley, R.B., Waller, L.J., Strauss, V., Geldenhuys, D., Underhill, L.G. \& Parsons, N.J. (2014). Release and survival of African penguin chicks abandoned before independence by moulting parents. PLoS ONE 9, e110794

Siegel, H.S. (1980) Physiological stress in birds. BioScience 30, 529-534

Stier, A., Viblanc, V.A., Massemin-Challet, S., Handrich, Y., Zahn, S., Rojas, E.R., Saraux, C., Le Vailliant, M., Prud'homme, O., Grosbellet, E., Robin, J-P., Bize, P. \& Criscuolo, F. (2014). Starting with a handicap: phenotypic differences between early- and lateborn king penguin chicks and their survival correlates. Func. Ecol. 28, 601-611

Tjørve, K.M.C. \& Underhill, L.G. (2009). Growth and its relationship to fledging success of African Black Oystercatcher, Haemotopus moquini, chicks. Zoology 112, 27-37

Vanstreels, R.E.T., Adornes, A.C., Canabarro, P.L., Ruoppolo, V., Amaku, M., da SilvaFilho, R.P. \& Catão-Dias, J.L. (2013). Female-biased mortality of Magellanic Penguins (Spheniscus magellanicus) on the wintering grounds. Emu 113, 128-134

Wilson, P.N. \& Osbourn, D.F. (1960). Compensatory growth after undernutrition in mammals and birds. Biol. Rev. 35, 324-361

Wimberger, K., Downs, C.T. \& Boyes, R.S. (2010). A survey of wildlife rehabilitation in South Africa: is there a need for improved management? Anim. Welf. 19, 481-499

Wolfaardt, A.C., Underhill, L.G., Altwegg, R. \& Visagie, J. (2008). Restoration of oiled African Penguins Spheniscus demersus a decade after the Apollo Sea Spill. Afr. J. Mar. Sci. $30,421-436$ 
515 Figure 1. Body condition index $(B C l)$ at admission of $(n=1455)$ African penguin chicks released (1) from or that died (0) during rehabilitation. The binomial GLMM fit (solid line) and $95 \%$ confidence intervals (black dashed lines) are shown. The dashed grey lines indicate (from right to left) the predicted survival rate for $\mathrm{BCl}=0.51$ (mean $\mathrm{BCl}$ in the reference cohort), for $\mathrm{BCl}=0.0$ (the proposed threshold for chick removal), and the $\mathrm{BCl}$ below which the probability of release was $<50 \%(-1.05)$.

Figure 2. The relationship between body condition index $(\mathrm{BCl})$ at admission of African penguin chicks and the time they spent in rehabilitation (days) for $(A)$ chicks that died $(n=$ $410)$ and $(B)$ chicks released $(n=1045)$. The negative binomial GLMM fit (solid line) and 95\% confidence intervals (dashed lines) are shown in each case.

Figure 3. A) Gompertz growth coefficients $\left(k_{G}\right)$ during rehabilitation of African penguin chicks in the $2012 / 13$ cohort $(n=220)$ released $(1)$ from or that died $(0)$ during rehabilitation. The binomial GLMM fit (solid line) and 95\% confidence intervals (dashed lines) are shown. B)

530 The relationship between $\mathrm{BCl}$ at admission and $k_{G}$ for chicks in 2012/13 that were released 531 ( $n=181)$. The LMM fit (solid line) and 95\% confidence intervals (dashed lines) are shown. 
532 Figures

533 Figure 1

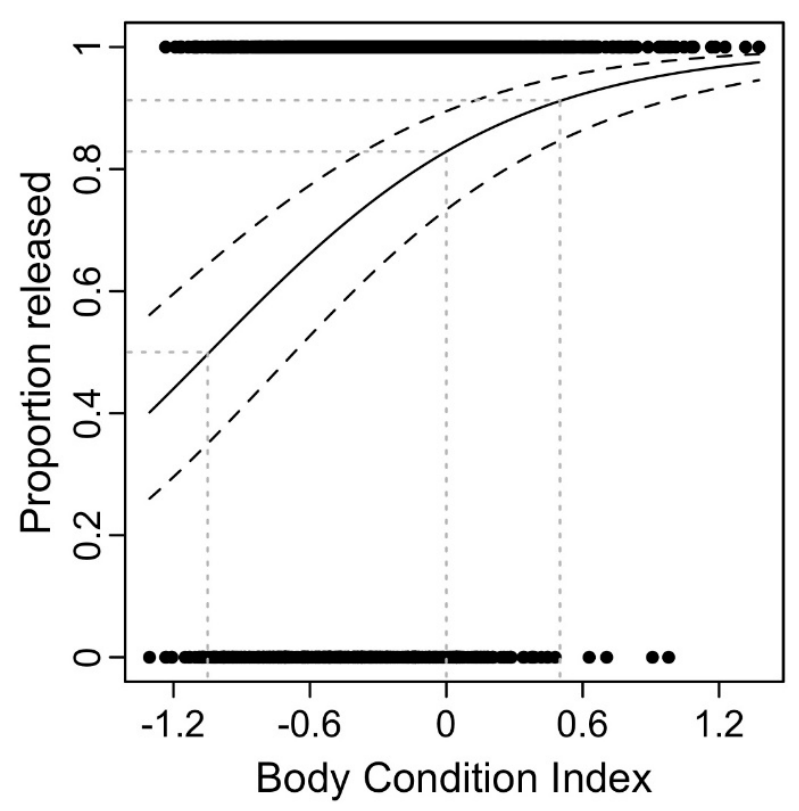

$535 \quad$ Figure 2
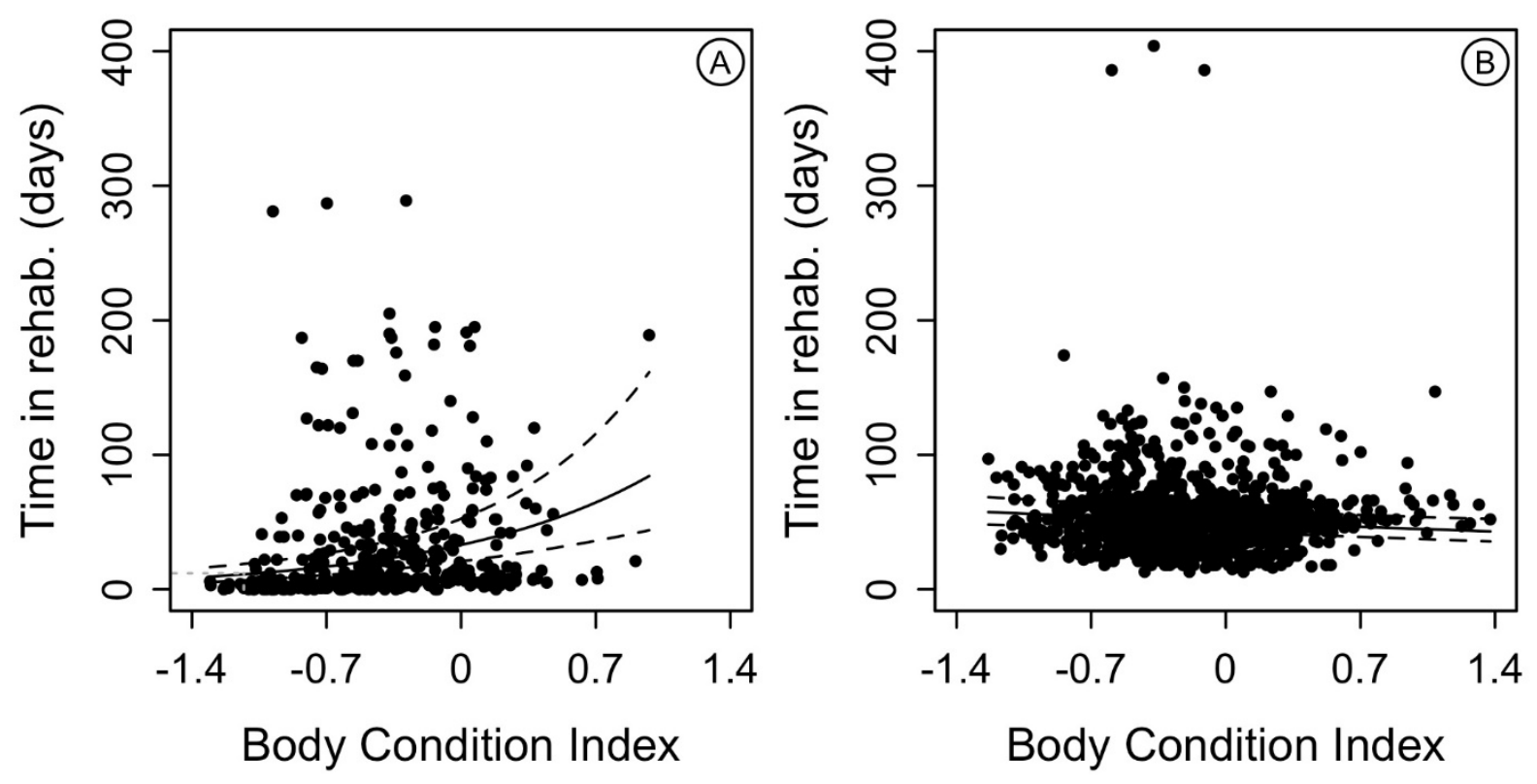
$539 \quad$ Figure 3

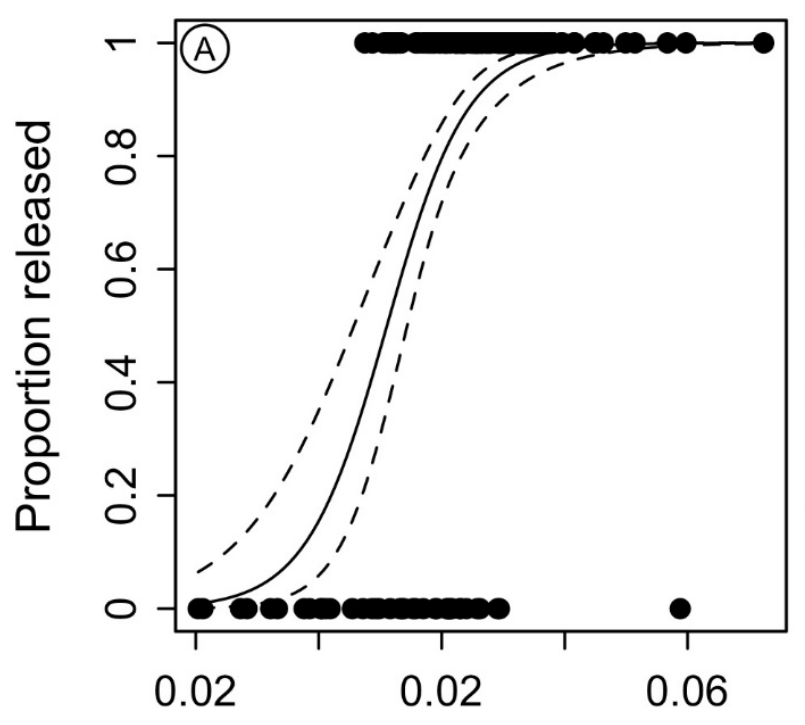

Growth coefficient

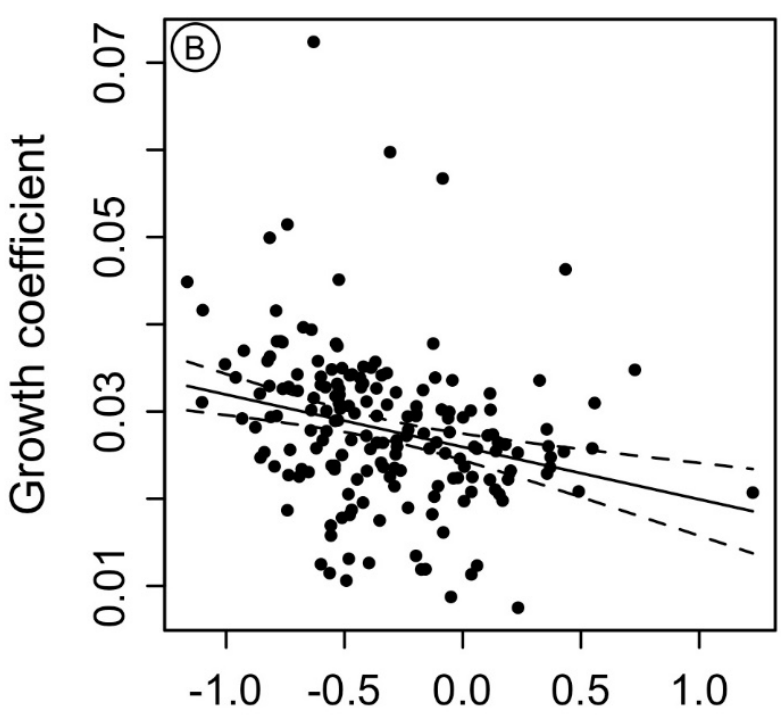

Body Condition Index 
543 Table 1. Results of the binary cross-validation using the test set of 100 chicks and model 544 predictions from the generalised-linear mixed-model relating rehabilitation outcome to $\mathrm{BCl}$ at 545 admission for $n=1455$ chicks (see Fig. 1 ).

\begin{tabular}{lccccc}
\hline & & \multicolumn{2}{c}{ Predicted } & \multirow{2}{*}{ Total } & \multirow{2}{*}{ \% correct } \\
& & Died & Released & & \\
\hline \multirow{2}{*}{ Observed } & Died & 1 & 31 & 32 & 3.1 \\
& Released & 0 & 68 & 68 & 100 \\
& \multicolumn{1}{c}{ Total } & 1 & 99 & 100 & 69 \\
\hline
\end{tabular}

Table 2. Model selection results for generalised-linear mixed-models relating morphometric measurements at admission to rehabilitation success of 173 African penguin chicks admitted to SANCCOB between September 2012 and February 2013 (2012/13 cohort).

\begin{tabular}{ccccccc}
\hline Model & $\mathbf{K}$ & AICc & $\Delta$ AICc & AICc Weight & Effect direction & Marginal $\mathbf{R}^{2}$ \\
\hline $\mathrm{BCl}+\mathrm{BL}+$ Mass & 5 & 202.5 & 0.00 & 0.298 &,,++- & 0.253 \\
$\mathrm{BCl}+\mathrm{BL}+\mathrm{Sex}$ & 5 & 202.7 & 0.23 & 0.266 &,,$++ \mathrm{M}$ & 0.252 \\
$\mathrm{BCl}+\mathrm{BL}$ & 4 & 202.9 & 0.43 & 0.240 &,++ & 0.243 \\
$\mathrm{BCl}+\mathrm{BL}+\mathrm{FT}$ & 5 & 203.7 & 1.15 & 0.167 &,,++- & 0.247 \\
Intercept only & 2 & 224.8 & 22.27 & 0.000 & $\mathrm{NA}$ & $\mathrm{NA}$ \\
\hline \multicolumn{7}{l}{ Models contributing to $90 \%$ of the summed AICc weight and the null model (intercept only) }
\end{tabular}
are shown. $\mathrm{K}=$ number of estimated parameters, $\mathrm{AICc}=$ Akaike's Information Criterion for small sample sizes, $\triangle \mathrm{AICc}=$ difference to the lowest $\mathrm{AICc}$ value, $\mathrm{AICc}$ Weight $=$ the relative support for each model. +/- indicates direction of each effect with respect to the order they appear in the model name. For Sex, $\mathrm{M}=$ higher average rehabilitation success for males. $\mathrm{BCl}=$ body condition index, $\mathrm{BL}=$ bill length, $\mathrm{FL}=$ flipper length, $\mathrm{FT}=$ foot length. NA = not applicable. The full model set is shown Table S2, Supporting Information. 